\title{
The chromium-51 complex of ethylenediamine tetraacetic acid as a soluble rumen marker
}

\author{
By A. M. DOWNES AND I. W. McDONALD \\ CSIRO, Division of Animal Physiology, The Ian Clunies Ross \\ Animal Research Laboratory, Prospect, N.S.W., Australia
}

(Received I3 August 1963-Accepted 28 October 1963)

In experiments on digestive function in ruminants, markers can be used to estimate the rate of movement of digesta, the volume of a viscus and the rates of absorption of solutes from the gut. The most widely used water-soluble marker is polyethylene glycol (PEG), which was introduced by Sperber, Hydén \& Ekman (1953). They found that the polymer with mean molecular weight 4000 was not degraded in the gut or absorbed, and described the use of PEG for the three purposes set out above.

Hydén (196I) has given a full mathematical treatment of the principles involved in the use of soluble markers to measure the rate of flow and volume of rumen fluid, and has indicated the inherent limitations of the method. He found that PEG gave a satisfactory estimate of rumen fluid volume (PEG space was approximately $95 \%$ of rumen water volume); in experiments of long duration (i.e. days or weeks), the flow rate could be calculated from the rate of fall in concentration of the marker; and in short-term experiments, the flow could be estimated from the amount of reference substance that had disappeared from the rumen during the experiment and the mean concentration of the marker in the rumen fluid.

However, a serious limitation in the use of PEG is the lack of a specific, sensitive and accurate method of analysis. All published methods have been based on precipitation from aqueous solution with subsequent gravimetric or turbidimetric measurement. Analytical difficulties have been recorded by Smith (1958), and Corbett, Greenhalgh, Gwynn \& Walker (1958) obtained incomplete recovery of PEG from the faeces of grazing cattle and sometimes from stall-fed cattle.

An alternative reference substance was sought and radioactivity was selected as a means for sensitive and completely specific analysis. 'The complex of ${ }^{51} \mathrm{Cr}$ with ethylenediamine tetraacetic acid $\left({ }^{51} \mathrm{Cr}\right.$ EDTA) was tested and compared with PEG. The results which are reported here showed ${ }^{51} \mathrm{Cr}$ EDTA to be a highly satisfactory soluble marker in sheep.

\section{EXPERIMENTAL}

\section{Animals}

Nine Merino wethers, one Merino ewe, and four cross-bred sheep were used. Five of the Merino wethers were 'normal', the rest of the sheep were fitted with rumen cannulas. The Merinos were fed once daily and were housed indoors in metabolism cages of the type described by Reis \& Schinckel (1961). Faecal collections from the 
wethers were made with the harness and bag described by Weston (1959), and the urine was allowed to run into the collector under the cage. The cross-bred sheep were kept indoors in single pens and were maintained, for another experiment, on a 'drought-feeding' régime that provided, once every 3 days, a mixture of wheaten chaff $675 \mathrm{~g}$, oat straw chaff $675 \mathrm{~g}$, crushed wheat $390 \mathrm{~g}$ and urea 9 or $18 \mathrm{~g}$.

\section{Preparation of ${ }^{51} \mathrm{Cr}$ EDTA}

Chromic chloride $\left(0.80 \mathrm{~g} \mathrm{CrCl}_{3} .6 \mathrm{H}_{2} \mathrm{O}\right.$ ) was dissolved in water (10 $\mathrm{ml}$ ) and labelled by the addition of an aqueous solution of $\left[{ }^{51} \mathrm{Cr}\right]$ chromic chloride (usually $\mathrm{I}-2 \mathrm{mc}$ in a negligible mass of chromic ions; from the Radiochemical Centre, Amersham, England). A solution of disodium ethylenediamine tetraacetate $\left(\mathrm{r} \cdot 00 \mathrm{~g}\right.$ in about $\left.20 \mathrm{ml} \mathrm{H}_{2} \mathrm{O}\right)$ was then added and the mixture heated at $100^{\circ}$ for $\mathrm{I} h$. The excess chromic ions were then precipitated as $\mathrm{Cr}(\mathrm{OH})_{3}$ by adding a slight excess of $\mathrm{NH}_{4} \mathrm{OH}$ to the hot solution. The suspension was cooled, filtered and washed with water. The filtrate, containing ${ }^{51} \mathrm{Cr}$ EDTA, was diluted to $100 \mathrm{ml}$. Suitable portions were dispensed as required. Duplicate I $\mathrm{ml}$ portions were diluted to $100 \mathrm{ml}$ or $250 \mathrm{ml}$ to provide standard solutions for the determination of radioactivity.

\section{Assay of ${ }^{51} \mathrm{Cr}$}

Several samples $(5 \mathrm{ml})$ of each of the standard solutions were pipetted into screwcap specimen tubes which fitted into the well of a thallium-activated $\mathrm{NaI}$ crystal (type $\mathrm{N}_{597}$;Ekco Electronics Ltd). These samples were counted at intervals, with each batch of unknowns an Ekco type $\mathrm{N}_{55}{ }^{\circ}$ scintillation counter and type $\mathrm{N}_{53}$ o scaler being used.

Duplicate samples $(5 \mathrm{ml})$ of urine, and of rumen liquor that had been strained through muslin, were similarly counted. The samples of faeces were mixed with water (I part moist faeces: 5 parts water by weight), macerated and $5 \mathrm{~g}$ portions dispensed into the counting tubes. Standards for the counting of faeces were prepared in the same way with known amounts of ${ }^{51} \mathrm{Cr}$ EDTA and non-radioactive faeces from the same animal.

At least 10000 counts were recorded for each sample, and the counting rates were corrected for the background rate (approximately ro counts/sec).

\section{Estimation of PEG}

The analytical method was that of Hydén (1955). The suspensions of PEG-4000 (Carbowax; Union Carbide Ltd) were read at $540 \mathrm{~m} \mu$ in a spectrophotometer. A linear relation of extinction to concentration of PEG was given by samples containing $0.04^{-0.09} \mathrm{mg} \mathrm{PEG} / \mathrm{ml}$ in the final solution as read. At lower concentrations of PEG, the turbidity was less than expected. The extinction increased with time after mixing the PEG solution with the trichloroacetic acid (TCA) $-\mathrm{BaCl}_{2}$ reagent, reached a maximum in about $6 \mathrm{~min}$ and was stable for at least $15 \mathrm{~min}$. It was found undesirable to allow the mixture to stand in the cuvette for long periods as a film of precipitate adhered to the glass and gave falsely high extinction readings. 
Blanks and two standards were prepared with each batch of analyses, as there was some variation in turbidity from day to day. A strict routine was adopted as the form of the precipitate could be influenced by minor changes in technique-for example, if tubes were shaken after addition of the TCA- $\mathrm{BaCl}_{2}$ reagent, the final turbidity was less than if the tubes were mixed by swirling.

As observed by Corbett et al. (1958), adequate dilution of rumen fluid or faeces before analysis proved to be necessary, otherwise recoveries were low. Hence, the dose administered had to be large enough to ensure an adequate concentration for analysis after dilution. Preliminary tests were done to ascertain the dilution required.

\section{Rumen marker experiments}

In each experiment an aqueous solution (about $400 \mathrm{ml})$ containing PEG (6-10 g) and ${ }^{51} \mathrm{Cr}$ EDTA (0.1 $\mathrm{g} ; 30-60 \mu \mathrm{c}$ ) was warmed to $39^{\circ}$ and added to the rumen of the sheep through its cannula. Samples of rumen liquor were taken $1,2,4,6,8$, 12 and, in some experiments, $24 \mathrm{~h}$ later and analysed for PEG and ${ }^{51} \mathrm{Cr}$. Each sample comprised three or four small portions taken from different parts of the rumen.

The 'half-times' of the markers were calculated from the slope of the curve given by plotting log concentration of marker against time; as the half-times were not critical in this work, a straight line was fitted to the experimental points by eye.

\section{RESULTS}

\section{Disappearance of ${ }^{51} \mathrm{Cr} E D T A$ and $P E G$ from the rumen}

Fifteen comparisons of the rates of disappearance of $P E G$ and of ${ }^{51} \mathrm{Cr}$ from the rumen were made (Table $\mathrm{I}$ ). In one series, the procedure was repeated on the 3 successive days of a 3 -day period with four sheep that were subjected to the 'droughtfeeding' régime. In another series an individual sheep was studied three times at intervals of about 4 weeks.

Some typical results are shown in Figs. I and 2. In each comparison the theoretical value of the ${ }^{51} \mathrm{Cr}$ : $\mathrm{PEG}$ ratio was calculated from the mass of PEG used and the counting rates of ${ }^{51} \mathrm{Cr}$ standards. The ratio was also calculated for each sample of rumen liquor, and was then expressed as a percentage of the theoretical value. The results (Figs. I and 2, Table I) show that, although individual values for samples taken during the first $\mathrm{I} 2 \mathrm{~h}$ differed by up to $20 \%$ from the theoretical value, there was no regular rise or fall in the ratio. The mean ${ }^{51} \mathrm{Cr}$ : $\mathrm{PEG}$ ratio for all of the experiments was $101.8 \%(\mathrm{SD} \pm 5.5)$ of the theoretical value. However, the mean ${ }^{51} \mathrm{Cr}$ : PEG ratio for one of the fifteen experiments ( $118 \%$ ) was more than three standard deviations higher than the theoretical value; if this result is discarded the mean for the other fourteen is $100.6( \pm 3.6 \%)$. Thus, over each $12 \mathrm{~h}$ period, the two markers gave the same results within experimental error. The results for the $24 \mathrm{~h}$ samples are also. shown in Figs. I and 2 but are only considered reliable when the concentration of PEG remained higher than $0.02 \mathrm{mg} / \mathrm{ml}$ in the final solution.

The concentration of each marker decreased approximately exponentially, with halftimes ranging from 8 to $4^{6} \mathrm{~h}$ (Table 2). The half-times for both markers tended to 
increase during the 3 -day period of the 'drought-feeding' régime. This tendency was

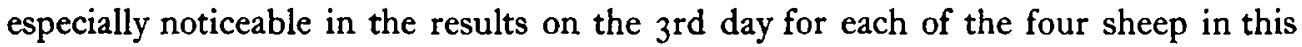
series.

Table I. Ratio, ${ }^{51} \mathrm{Cr}$ :polyethylene glycol in the rumen liquor after administration of ${ }^{51} \mathrm{Cr}$-ethylenediamine tetraacetic acid and PEG

\begin{tabular}{|c|c|c|c|c|c|c|}
\hline \multirow[b]{2}{*}{$\begin{array}{c}\text { Sheep } \\
\text { no. }\end{array}$} & \multirow[b]{2}{*}{ Expt } & \multirow[b]{2}{*}{ Day } & \multicolumn{2}{|c|}{ Dose } & \multicolumn{2}{|c|}{ Ratio, ${ }^{81} \mathrm{Cr}$ : PEG } \\
\hline & & & $\begin{array}{c}{ }^{61} \mathrm{Cr} \\
\mathrm{ED}^{\prime} \mathrm{TA}^{*} \\
(\mu \mathrm{c})\end{array}$ & $\begin{array}{c}\text { PEG } \\
(\mathrm{g})\end{array}$ & $\begin{array}{c}\% \text { of } \\
\text { theoretical }\end{array}$ & Mean \pm SD \\
\hline 218 & 3-day 'drought-feeding' $t$ & $\begin{array}{l}\mathbf{I} \\
2 \\
3\end{array}$ & $\begin{array}{l}30 \\
30 \\
30\end{array}$ & $\begin{array}{l}6 \\
6 \\
6\end{array}$ & $\begin{array}{c}99 \cdot 0 \\
95 \cdot 5 \\
97 \cdot 0\end{array}$ & \\
\hline 210 & 3-day 'drought-feeding' $t$ & $\begin{array}{l}1 \\
2 \\
3\end{array}$ & $\begin{array}{l}30 \\
30 \\
30\end{array}$ & $\begin{array}{l}6 \\
6 \\
6\end{array}$ & $\begin{array}{l}99 \cdot 5 \\
98 \cdot 0 \\
99 \cdot 5\end{array}$ & \\
\hline 231 & 3-day 'drought-feeding' $\ddagger$ & $\begin{array}{l}1 \\
2 \\
3\end{array}$ & $\begin{array}{l}56 \\
56 \\
56\end{array}$ & $\begin{array}{l}8 \\
8 \\
8\end{array}$ & $\begin{array}{l}101 \cdot 5 \\
101 \cdot 0 \\
106 \cdot 0\end{array}$ & I OI $\cdot 8 \pm 5 \cdot 5$ \\
\hline $2 I I$ & 3-day 'drought-feeding' $\ddagger$ & $\begin{array}{l}1 \\
2 \\
3\end{array}$ & $\begin{array}{l}56 \\
56 \\
56\end{array}$ & $\begin{array}{l}8 \\
8 \\
8\end{array}$ & $\begin{array}{l}106 \cdot 0 \\
108 \cdot 0 \\
118 \cdot 0\end{array}$ & \\
\hline $58 x$ & Daily feeding $\S$ & $\begin{array}{l}I \\
2 \\
3\end{array}$ & $\begin{array}{l}57 \\
57 \\
59\end{array}$ & $\begin{array}{l}10 \\
10 \\
10\end{array}$ & $\begin{array}{r}103 \cdot 5 \\
96 \cdot 5 \\
99 \cdot 0\end{array}$ & \\
\hline
\end{tabular}

* Always contained in about o. g Cr EDTA.

+ In each experiment, samples of rumen liquor were taken $1,2,4,6,8$ and $12 \mathrm{~h}$ after injection of ${ }^{81} \mathrm{Cr}$ EDTA and PEG into the rumen, and were analysed for ${ }^{51} \mathrm{Cr}$ and PEG. The ratio given is the mean for each set of six samples. The theoretical value was calculated from the mass of PEG and the counting rates of the ${ }^{51} \mathrm{Cr}$ standards.

$\ddagger$ These experiments were performed on successive days. The sheep were fed once only at the beginning of the Ist day.

$\S$ These experiments were performed at intervals of about 4 weeks.

If instantaneous mixing of the markers with the rumen contents had occurred, extrapolation of the curves in Figs. 1 and 2 should give the concentration of marker at zero time. From this value and the total amount of marker injected, the total volume of rumen liquor should be calculable. The results calculated in this way for each marker are shown in Table 2. The zero-time concentration was corrected, when necessary, by subtracting the concentration of marker in a sample of rumen liquor taken just before each injection.

\section{Recovery of ${ }^{51} \mathrm{Cr}$ in urine and faeces after intraruminal administration of ${ }^{51} \mathrm{Cr}$ EDTA}

In the first series of experiments five sheep were each given orally a single dose of ${ }^{51} \mathrm{Cr}$ EDTA mixed with I day's food, and one of the fistulated sheep was given a similar dose directly through its cannula. In each instance the amount of ${ }^{51} \mathrm{Cr}$ excreted in the urine and faeces was measured. Various masses of the marker were used, and once the animal was dosed with non-radioactive $\mathrm{Cr}$ EDTA for 4 days before the radioactive dose was given. The results (Table 3, Fig. 3) showed that $85-91 \%$ 
of the dose was recovered in the faeces excreted during the first 9 or 10 days, after which time small amounts of ${ }^{51} \mathrm{Cr}$ were still being excreted. Some ${ }^{51} \mathrm{Cr}$ always appeared in the urine, the maximum amount being $4.7 \%$ of the dose in the first 7 days.

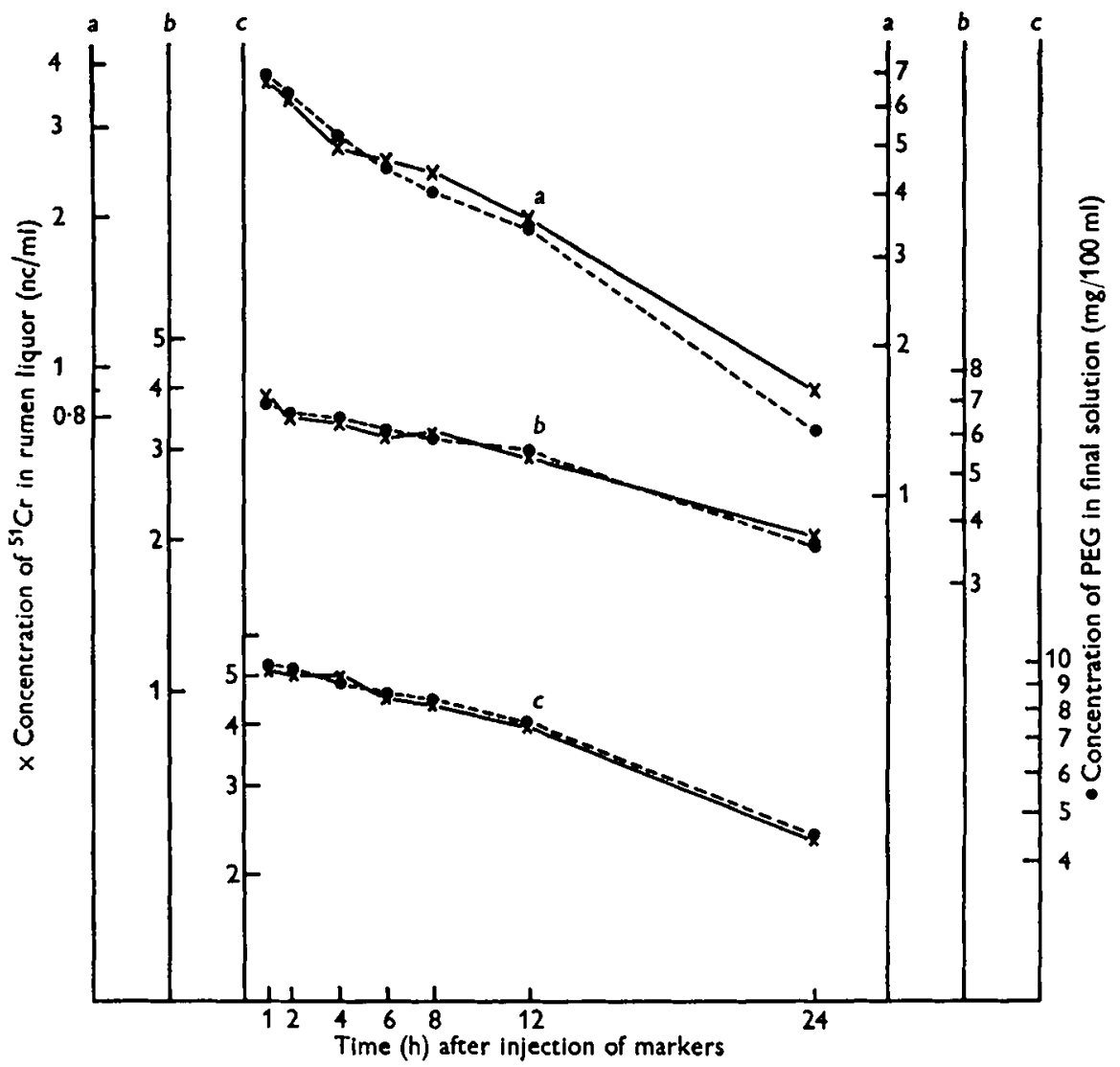

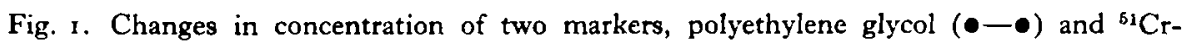
cthylenediamine tetraacetic acid $(x-x)$ placed in aqueous solution in the rumen of sheep 218 . The two markers were injected into the rumen together in a single solution on successive days $(a, b, c)$ during a 3 -day period in which the sheep were fed once only at the beginning of the rst day. The ordinates are plotted to equate the separate concentrations as administered; thus if the markers behaved identically and there were no errors in estimating concentration, the pairs of curves should be congruent.

In another experiment three doses of a mixture of ${ }^{51} \mathrm{Cr}$ EDTA and $\mathrm{PEG}$ were given through a rumen fistula to the same sheep at intervals of about 4 weeks. Samples of rumen liquor were taken at intervals during the first $12 \mathrm{~h}$ after each dose (see p. 155 ), and the recovery of the markers in the urine and faeces was measured. The results (Table 4, Fig. 4) showed that about $95 \%$ of the dose of ${ }^{51} \mathrm{Cr}$ (corrected for the amount taken in rumen liquor samples) appeared in the faeces and $2.5 \%$ (also corrected) in the urine during the 5 days after each dose. The recovery of PEG in the faeces was slightly lower than that of the ${ }^{51} \mathrm{Cr}$. In each experiment, no significant quantity of PEG could be detected in the urine. 


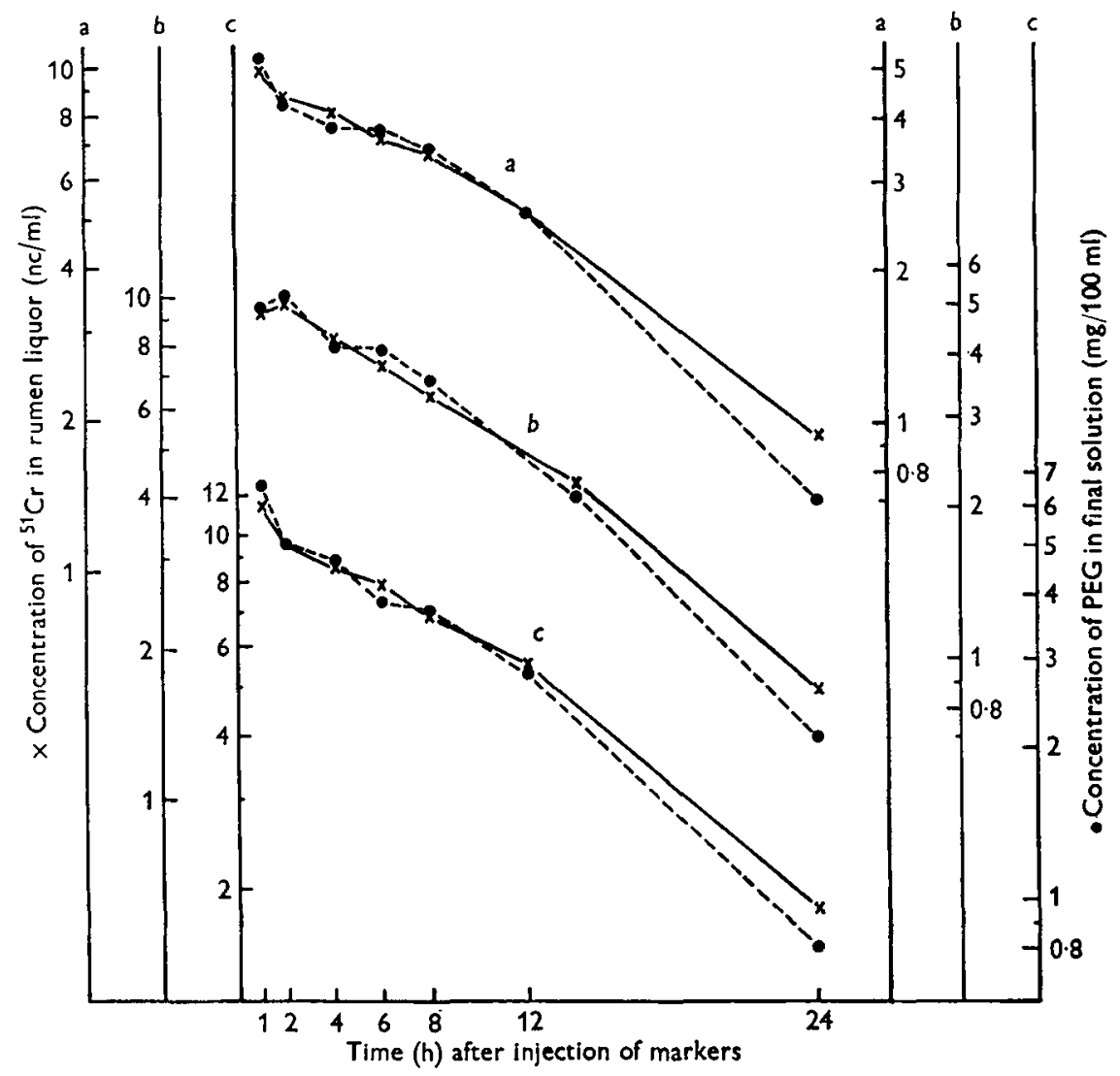

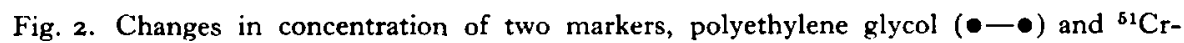
ethylenediamine tetraacetic acid $(x-x)$ placed in aqueous solution in the rumen of sheep $5^{81}$. The three experiments were carried out at intervals of about 4 weeks; otherwise they were as described in the legend to Fig. $x$.

\section{Fate of intravenously administered ${ }^{51} \mathrm{Cr}$ EDTA}

A dose of ${ }^{51} \mathrm{Cr}$ EDTA $(20 \mu \mathrm{c} ; 80 \mathrm{mg}$ ) was injected into the left jugular vein of a Merino wether fitted with a rumen cannula. Samples of blood and of rumen liquor were taken at intervals during the $5 \mathrm{~h}$ after the dosing. As shown in Fig. 5 , the radioactivity disappeared rapidly from the circulation, the specific activity $v$. time curve being resolvable into two exponential lines with half-times of approximately 8 and $83 \mathrm{~min}$, respectively. No radioactivity was detectable in any of the six rumen liquor samples taken during the $5 \mathrm{~h}$ period. On the assumption that the volume of rumen liquor was 61 ., it was estimated that the presence in the liquor of approximately $4 \%$ of the dose would have been detectable.

In another experiment a ewe and a wether, both Merinos, were also given intravenously ${ }^{51} \mathrm{Cr}$ EDTA ( $16 \mu \mathrm{c} ; 5^{\circ} \mathrm{mg}$ ) and the amounts of ${ }^{51} \mathrm{Cr}$ excreted in the urine and faeces were measured. No ${ }^{51} \mathrm{Cr}$ was detectable in the faeces of either sheep, and over $90 \%$ was recovered in the urinc (Table 3$)$. The bulk of the excreted ${ }^{51} \mathrm{Cr}(86.5 \%$ of the dose in each experiment) appeared in the Ist day's urine. 
Table 2. Comparisons of ${ }^{51} \mathrm{Cr}$-ethylenediamine tetraacetic acid and polyethylene glycol as markers for estimation of rumen volume and half-time of solutes

\begin{tabular}{|c|c|c|c|c|c|}
\hline \multirow{2}{*}{$\begin{array}{l}\text { Sheep } \\
\text { no. }\end{array}$} & \multirow[b]{2}{*}{ Expt } & \multicolumn{2}{|c|}{$\begin{array}{l}\text { Half-time in } \\
\text { rumen }(\mathrm{h})\end{array}$} & \multicolumn{2}{|c|}{$\begin{array}{l}\text { Estimated volume of } \\
\text { rumen liquor (1.)* }\end{array}$} \\
\hline & & ${ }^{51} \mathrm{Cr}$ & PEG & ${ }^{51} \mathrm{Cr}$ & PEG \\
\hline \multirow[t]{2}{*}{218} & 3 -day 'drought-feeding' $\dagger$ & I I & 10 & $8 \cdot 0$ & $7 \cdot 5$ \\
\hline & & $\begin{array}{l}27 \\
32\end{array}$ & $\begin{array}{l}34 \\
28\end{array}$ & $\begin{array}{r}10.3 \\
9.3\end{array}$ & $\begin{array}{l}9 \cdot 3 \\
8 \cdot 2\end{array}$ \\
\hline 210 & 3-day 'drought-feeding' $\nmid$ & $\begin{array}{l}17 \\
18 \\
46\end{array}$ & $\begin{array}{l}15 \\
14 \\
36\end{array}$ & $\begin{array}{l}6.9 \\
8.9 \\
7 \cdot 7\end{array}$ & $\begin{array}{l}6 \cdot 8 \\
7 \cdot 6 \\
7 \cdot 0\end{array}$ \\
\hline \multirow[t]{2}{*}{231} & 3-day 'drought-feeding' $\dagger$ & $\begin{array}{l}8 \\
8\end{array}$ & $\begin{array}{l}8 \\
8\end{array}$ & $\begin{array}{l}5 \cdot 3 \\
6 \cdot 4\end{array}$ & $\begin{array}{l}5 \cdot 5 \\
6 \cdot 2\end{array}$ \\
\hline & & 14 & 12 & $7 \cdot 2$ & $7 \cdot 2$ \\
\hline \multirow[t]{3}{*}{2 II } & 3-day 'drought-feeding' $\dagger$ & 12 & 12 & $6 \cdot 1$ & $6 \cdot 4$ \\
\hline & & 13 & 12 & $7 \cdot 0$ & $7 \cdot 8$ \\
\hline & & 20 & 17 & $6 \cdot 3$ & $7 \cdot 5$ \\
\hline \multirow[t]{3}{*}{$58 \mathrm{I}$} & Daily feedingt & 12 & I I & $5 \cdot 6$ & $5 \cdot 3$ \\
\hline & & 10 & 10 & $5 \cdot 3$ & $5 \cdot 0$ \\
\hline & & II & 10 & 5.4 & $5^{\cdot 2}$ \\
\hline
\end{tabular}

- Calculated from total dose and zero-time concentration of marker, corrected for amount present just before each injection.

$\uparrow$ These experiments were performed on successive days. The sheep were fed once only at the beginning of the rst day.

I These experiments were performed at intervals of about 4 weeks.

Table 3. Recovery of ${ }^{51} \mathrm{Cr}$ in urine and faeces after dosing with ${ }^{51}$ Cr-ethylenediamine tetraacetic acid

\begin{tabular}{|c|c|c|c|c|c|c|}
\hline \multirow{2}{*}{$\begin{array}{c}\text { Sheep } \\
\text { no. }\end{array}$} & \multicolumn{3}{|c|}{ Dose of ${ }^{51} \mathrm{Cr}$ EDTA } & \multicolumn{3}{|c|}{ Dose recovered* $(\%)$} \\
\hline & $\mathrm{mg}$ & $\mu \mathrm{c}$ & Route & Faeces & Urine & Total \\
\hline $303 \uparrow$ & 210 & 105 & Rumen fistula & 84.4 (10) & $4 \cdot 7(7)$ & $89 \cdot I$ \\
\hline $318 t$ & 210 & 105 & In food & $87.5(9)$ & $3 \cdot 6(7)$ & $9 I \cdot I$ \\
\hline $300 t$ & $100 \$$ & 45 & In food & $89.9(9)$ & $3 \cdot 2(4)$ & $93 \cdot I$ \\
\hline $329 \pm$ & 100 & 45 & In food & $9 \times 2(9)$ & $4 \cdot 5(5)$ & $95 \cdot 7$ \\
\hline $337 \dagger$ & 100 & 45 & In food & $91 \cdot 3(10)$ & $2 \cdot 6(4)$ & 93.9 \\
\hline 3 rot & 1350 & 45 & In food & $85.8(9)$ & - & - \\
\hline 225 & 50 & 16 & Intravenous & 0 & $91 \cdot 0(6)$ & $91 \cdot 0$ \\
\hline 325 & 50 & 16 & Intravenous & $\circ$ & $95.6(6)$ & $95 \cdot 6$ \\
\hline
\end{tabular}

- Figures in parentheses are the number of days during which collections were made.

$\dagger$ Daily ration: $150 \mathrm{~g}$ lucerne chaff, $150 \mathrm{~g}$ wheaten chaff, $100 \mathrm{~g}$ gluten.

I Daily ration: $150 \mathrm{~g}$ lucerne chaff, $\mathrm{I} 50 \mathrm{~g}$ wheaten chaff, $100 \mathrm{~g}$ starch.

$\S$ Dosed with non-radioactive Cr EDTA at rate of $250 \mathrm{mg} /$ day on the 4 days immediately preceding the radioactive dose.

\section{DISCUSSION}

There is now a large body of evidence to support the contention that PEG is, in principle, a satisfactory soluble marker for research on gastro-intestinal function. It has therefore been used as a reference substance to test the applicability of ${ }^{51} \mathrm{Cr}$ EDTA.

The evidence presented above shows clearly that ${ }^{51} \mathrm{Cr}$ EDTA and PEG move together in the gastro-intestinal contents, and it may therefore confidently be concluded that ${ }^{51} \mathrm{Cr}$ EDTA is a satisfactory marker. 


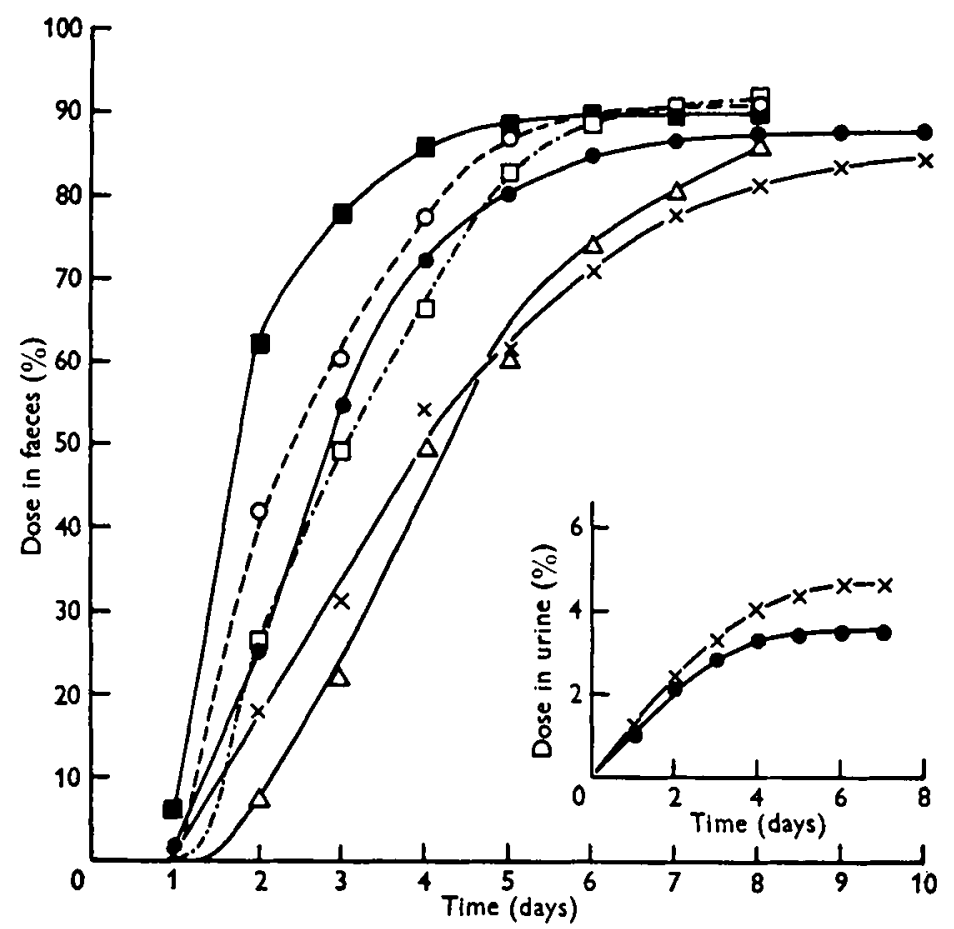

Fig. 3. Recovery of ${ }^{51} \mathrm{Cr}$ in urine and faeces after intraruminal administration of ${ }^{51} \mathrm{Cr}$-ethylenediamine tetraacetic acid. Sheep: $300, \bullet ; 303, \times ; 310, \Delta ; 318, \bullet ; 329,0 ; 337$, 口 (see Table 3).

Table 4. Percentage recoveries of ${ }^{51} \mathrm{Cr}$ and of polyethylene glycol from a sheep dosed with ${ }^{51}$ Cr-ethylenediamine tetraacetic acid $+P E G$ through a rumen fistula

\begin{tabular}{|c|c|c|c|c|c|c|c|c|}
\hline \multirow{2}{*}{$\begin{array}{c}\text { Dose } \\
\text { no. }\end{array}$} & \multicolumn{2}{|c|}{ Rumen liquor } & \multicolumn{2}{|c|}{ Faeces } & \multicolumn{2}{|c|}{ Urine } & \multicolumn{2}{|c|}{ Total } \\
\hline & ${ }^{51} \mathrm{Cr}$ & PEG & ${ }^{81} \mathrm{Cr}$ & PEG & ${ }^{81} \mathrm{Cr}$ & PEG $†$ & ${ }^{81} \mathrm{Cr}$ & PEG \\
\hline $\begin{array}{l}1 \\
2 \\
3\end{array}$ & $\begin{array}{r}12.5 \\
8.8 \\
8.7\end{array}$ & $\begin{array}{r}12 \cdot 0 \\
8 \cdot 9 \\
9 \cdot 0\end{array}$ & $\begin{array}{l}83.5 \\
85.3 \\
85.2\end{array}$ & $\begin{array}{l}77 \cdot 0 \\
81 \cdot 7 \\
82 \cdot 6\end{array}$ & $\begin{array}{l}2 \cdot 5 \\
2 \cdot 2 \\
2 \cdot 0\end{array}$ & $\begin{array}{l}\text { Trace } \\
\text { Trace } \\
\text { Trace }\end{array}$ & $\begin{array}{l}98 \cdot 5 \\
96 \cdot 3 \\
95.9\end{array}$ & $\begin{array}{l}89 \cdot 0 \\
90 \cdot 6 \\
91.6\end{array}$ \\
\hline
\end{tabular}

- Removed in sampling for analysis.

+ Trace indicates a negligibly small precipitate occurring in the analysis; no specific test for PEG in small amounts has been described.

${ }^{51} \mathrm{Cr}$ EDTA presents the very important advantage that the analytical procedure is quite specific and highly accurate over a wide range of concentrations. As ${ }^{51} \mathrm{Cr}$ emits $\gamma$-rays $(0.323 \mathrm{MeV})$ it can be counted easily in a scintillation counter with very simple preparation of the specimens for analysis. By contrast, the analysis for PEG is non-specific, and it is known that substances in the gut interfere and that appreciable errors occur even under good analytical conditions. Further, it is not practicable to estimate PEG in low concentrations. Hence one is obliged to use a large dose or to run an experiment for a short period of time.

The only theoretical disadvantage of ${ }^{51} \mathrm{Cr}$ EDTA is the slight absorption and subsequent excretion in the urine. In practice, this is not likely to be troublesome, as 
appropriate corrections can be made. There are, however, the usual difficulties associated with the use of any radioactive substance, but it is noteworthy that ${ }^{51} \mathrm{Cr}$ is considered to be one of the least hazardous isotopes (International Atomic Energy

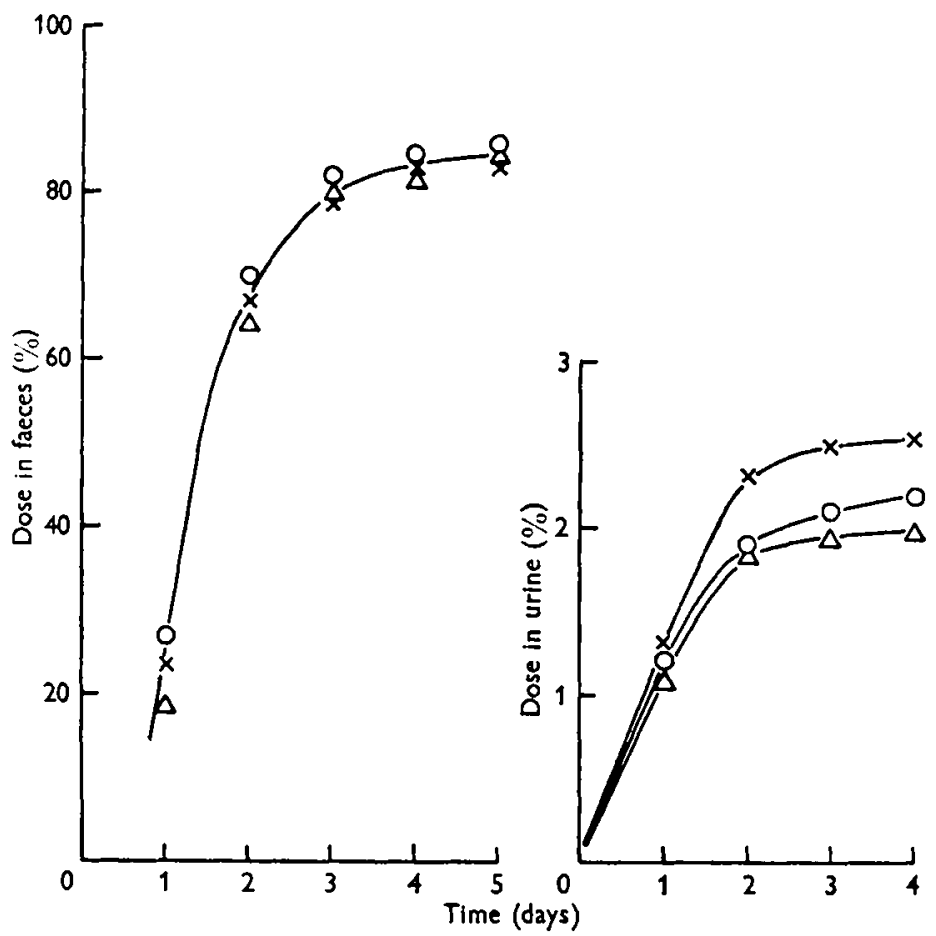

Fig. 4. Recovery of ${ }^{51} \mathrm{Cr}$ in urine and faeces of sheep 581 after intraruminal administration of ${ }^{51} \mathrm{Cr}$-ethylenediamine tetraacetic acid in three doses $(x, 0, \Delta)$ at intervals of about 4 weeks.

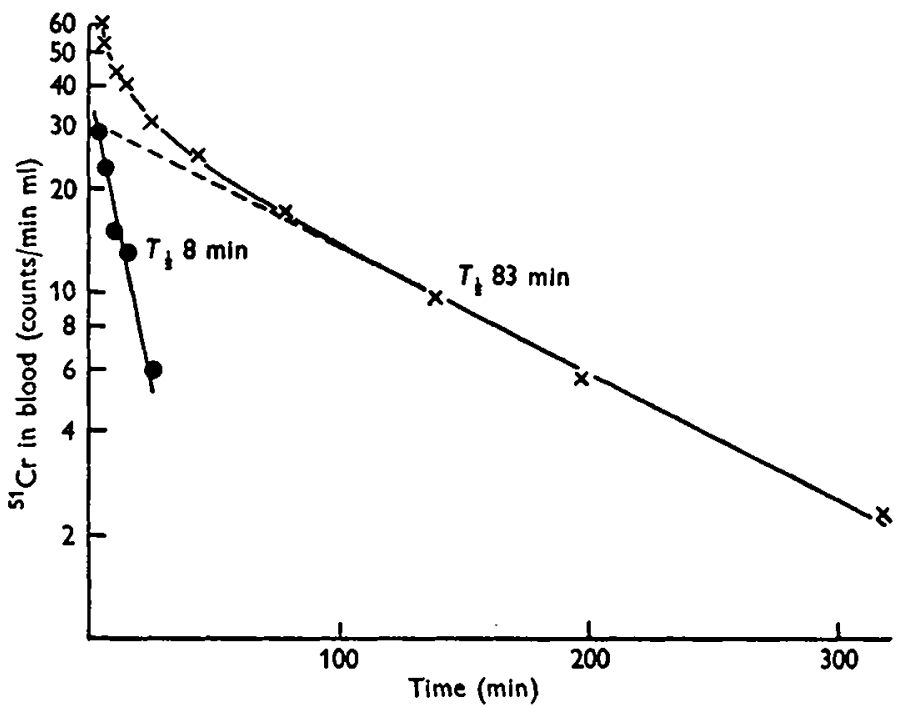

Fig. 5. Rate of disappearance of ${ }^{51} \mathrm{Cr}$ from the circulation after intravenous administration of ${ }^{51} \mathrm{Cr}$-ethylenediamine tetraacetic acid. The curve for the specific activity $(x-x)$ of the blood was resolved into two exponentials with half-times of 8 and $83 \mathrm{~min}$. 
Agency, 1958). With careful attention to the standard procedures for handling radioisotopes, ${ }^{51} \mathrm{Cr}$ can be used under most experimental conditions, either in the laboratory or in the field. Since ${ }^{51} \mathrm{Cr}$ has a half-life of 27.8 days, each preparation can be used over a period of several months.

Although our experiments have been confined to sheep, there is no reason to doubt that this marker will prove equally valuable in studies of gastro-intestinal function in other species.

The most stable complexes formed by EDTA are those with $\mathrm{Fe}^{3+}$ and $\mathrm{Cr}^{3+}$ with stability constants of $10^{25}$ and $10^{24}$ respectively (Schwarzenbach \& Freitag, 195 I). Of the isotopes of these two metals, ${ }^{51} \mathrm{Cr}$ was considered to be the most suitable for our purpose, because it is the cheapest and safest.

\section{SUMMARY}

I. The ethylenediamine tetraacetic acid complex with chromium labelled with ${ }^{51} \mathrm{Cr}$ was prepared and tested as a soluble marker for experiments on gastro-intestinal function of the sheep.

2. Fifteen comparisons were made of the rates of disappearance from the rumen of ${ }^{51} \mathrm{Cr}$-ethylenediamine tetraacetic acid and of polyethylene glycol (PEG-4000, Carbowax), a widely used marker. The two markers gave the same results within experimental error, the concentration of each decreasing approximately exponentially, with half-times ranging from 8 to $4^{8} \mathrm{~h}$. For sheep fed once every 3 days, the half-time tended to increase during the 3 -day period.

3. The recovery of ${ }^{51} \mathrm{Cr}$ in the faeces and urine was measured after intraruminal administration of ${ }^{51} \mathrm{Cr}$-ethylenediamine tetraacetic acid to six sheep. Most $(85-9 \mathrm{r} \%)$ of each dose was recovered in the faeces excreted during the first 9 or 10 days, after which time small amounts of ${ }^{51} \mathrm{Cr}$ were still being excreted. Some ${ }^{51} \mathrm{Cr}$ always appeared in the urine, the maximum amount being $4.7 \%$ of the dose.

4. After intravenous administration of ${ }^{51} \mathrm{Cr}$-ethylenediamine tetraacetic acid no ${ }^{51} \mathrm{Cr}$ was detectable in the rumen liquor or faeces, and over $90 \%$ of the ${ }^{51} \mathrm{Cr}$ was recovered in the urine.

5. It was concluded that ${ }^{51} \mathrm{Cr}$-ethylenediamine tetraacetic acid is a satisfactory soluble marker in spite of the slight absorption and subsequent excretion in the urine. The estimation of ${ }^{51} \mathrm{Cr}$ is simple, accurate, and specific.

We wish to thank Messrs D. A. Shutt and A. R. Till for their skilful technical assistance.

\section{REFERENCES}

Corbett, J. L., Greenhalgh, J. F. D., Gwynn, P. E. \& Walker, D. (1958). Brit. F. Nutr. 12, 266.

Hydén, S. (1955). K. LantbrHögsk. Ann. 22, 139.

Hydén, S. (1961). K. LantbrHögsk. Ann. 27, 51 .

International Atomic Energy Agency (1958). Safety Series no. I, Safe Handling of Radioisotopes, p. 35. Vienna: I.A.E.A.

Reis, P. J. \& Schinckel, P. G. (1961). Aust. F. agric. Res. 12, 335.

Schwarzenbach, G. \& Freitag, E. (1951). Helv. chim. acta, 34, 1503.

Smith, R. H. (1958). Nature, Lond., 182, 260.

Sperber, I., Hydén, S. \& Ekman, J. (1953). K. LantbrHögsk. Ann. 20, 337.

Weston, R. H. (1959). Aust. F. agric. Res. 10, 865. 